\title{
Borsa İstanbul'da Sürü Davranışı Varlığının Test Edilmesi: Borsa İstanbul Üzerine Bir Uygulama
}

\author{
Serdar KUZU 1*(D), İsmail Erkan ÇELIK ${ }^{2}$ \\ ${ }^{1}$ Assoc. Prof. Dr, İstanbul University-Cerrahpaşa, Vocational School of Social Sciences, Department of \\ Accounting and Tax, İstanbul, Turkey \\ ${ }^{2}$ Asst. Prof. Dr., Doğuş University, Faculty of Economics and Administrative Sciences, Department of \\ Economics, İstanbul, Turkey
}

Geliş Tarihi/Received: 20.08.2020

Kabul Tarihi/Accepted: 18.09.2020

Araştırma Makalesi/Research Article

\section{ÖZET}

Çalışmanın temel amacı Borsa İstanbul'da sürü davranışı olup olmadığını belirlemektir. Davranışsal finans teorilerini, Geleneksel finans teorilerinden ayıran en önemli noktalardan biri yatırımcıların rasyonel olmayan bilişsel özellikler sergilemesidir. Sermaye Piyasası Kurulu 04.06.2020 tarihinde yaptığı basın açıklamasına göre gözetim ve denetim faaliyetleri neticesinde, Facebook, Twitter gibi sosyal medya mecraları ile Whatsapp, Telegram v.b. iletişim sistemlerinde oluşturulan üyelik bazlı gruplar üzerinden, aralarında SPK tarafından yetkilendirilmiş yatırım danışmanlığı ve benzeri sermaye piyasası faaliyeti izni olmayan kişi veya kişilerce, yatırımcıların yönlendirilerek mağdur edilmeye yönelik eylemlerin devam ettiği görülmektedir. $\mathrm{Bu}$ durum yatırımcıların çeşitli şartlar ve kurallar ile dayatılmış birtakım inançların, bir topluluk ya da grup tarafından yayılması şeklinde adlandırılan sürü davranışından etkilenip etkilenmediği hususun gerekliliğini ortaya çıkmıştır. Sermaye piyasalarında sürü davranışının varlığını tespit etmek için çalışmada 2000-2020/6 dönemleri ile Borsa İstanbul'da işlem gören hisse senetleri ve piyasa göstergesi olarak BIST 100 endeksi kullanılmıştır. Sürü davranışı Christie ve Huang (1995) ve Chang, Cheng ve Khorana (2000) tarafından geliştirilen hisse senedi getirilerinin yatay kesit değişkenliğine dayalı yöntem kullanılarak analiz edilmiştir. Çalışma sonucunda ekstrem hareketlerin görüldüğü piyasalarda bir durumda bir başka deyişle alçalan ya da yükselen piyasalarda yatay kesit standart sapmayı azaltacağı hipotezi doğrulanamamakta ve kullanılan veri setinde ortaya koyulan yöntem ile sürü davranışına rastlanılmadığı sonucuna ulaşılmıştır.

Anahtar kelimeler: Sürü Davranışı, Borsa İstanbul, Hisse Senedi, C-H Modeli.

* Sorumlu yazar/Corresponding author

E-mail/e-ileti: serdar.kuzu@istanbul.edu.tr 


\title{
Testing Existance of Herd Behavior in Borsa Istanbul: A Study in Borsa Istanbul
}

\begin{abstract}
The main purpose of the study is not to know that there is no herd behavior in Borsa Istanbul. It is that investors exhibit non-rational cognitive traits. According to the press release of the Capital Markets Board on 04.06.2020, as a result of the surveillance and inspection activities, social media channels such as Facebook, Twitter, Whatsapp, Telegram etc. It is observed that the actions of individuals or persons who do not have permission for investment consultancy and similar capital market activities, among which are authorized by the CMB, continue to lead investors through the membership-based groups established in communication systems. This situation arises whether investors are affected by herd behavior, which is the spread of certain beliefs imposed by various conditions and rules, by a community or group.

In order to determine the existence of herd behavior in capital markets, stocks traded in Borsa Istanbul between 2000-2020 / 6 and BIST 100 index as a market indicator were used in the study. Herd behavior was analyzed using the method based on cross-sectional variability of stock returns developed by Christie and Huang (1995) and Chang, Cheng and Khorana (2000). As a result of the study, the hypothesis that in a situation where extreme movements are observed, in other words, the cross section would decrease the standard deviation in descending or rising markets, could not be confirmed and it was concluded that herd behavior was not encountered with the method used in the data set.
\end{abstract}

Keywords: Herding Theory, Stock Market Istanbul, Stock, C-H Model.

\section{GİIŞ}

Davranışsal finansın temel konuları içerisinde yer alan sürü davranışı, kişinin fikirleri doğrultusunda hareket etmeyip, içinde bulunduğu grubun davranışları ya da bilgilerinden etkilenerek bu doğrultuda hareket etmesi ya da karar almasıdır.

Literatürde yapılan amprik çalışmaların çoğunun hisse senedi piyasası ve getirisi üzerinde yoğunlaştığı görülmektedir. Yapılan çoğu çalışmada kullanılan parametreler ile hisse senetleri arasında ilişkinin tam olarak ortaya öngörülememiştir. $\mathrm{Bu}$ durum çalışmalarda yatırımcıların karar verme süreçlerinde istatistiki, ekonometri ve matematiksel bilgilerin etkin bir şekilde kullanılmadığı rasyonelliği tam manasıyla dikkate almadıklarını göstermektedir. Bir başka ifadeyle yapılan çalışmalarda ortaya konulması istenen durumun sınırlı rasyonellikle 
mekanik olarak ortaya koyulmaktadır. Bu durum bilim adamlarını yatırımcı davranışlarını anlayabilme hususunda psikoloji ve sosyoloji nin çalışmalarda irdelenmesi gerektiği hususunda yönelmelerine neden olmuştur. Çünkü insan duyguları, sezgileri olan, bilinçaltı dürtülere sahip, sosyal çevreden etkilenebilen ve etkileyebilen bir varlıktır. Yapılan çalışmaların sonucunda finans literatüründe, psikoloji ve sosyoloji biliminin bulgularının ekonomi alanına aktarılması ile yeni bir araştırma alanı olan davranışsal finans ortaya çıkmıştır. Bu noktada davranışsal yaklaşımı savunan bilim adamları, insanın ekonomik kararlarına psikolojik faktörlerin etkilerinin ve boyutlarını ortaya koyan çeşitli yayımlara da bu çalışmada yer verilmiştir. Daniel Kahneman ve Amos Tversky yatırımcıların bilişsel ve psikolojik davranışlarının finansal piyasalara etkisini ortaya koyan; Beklenti Teorisi, yatırımcı psikolojisi ve hisse senedi fiyatlarının tahmin edilebilirliği, Zihinsel Muhasebe Teorisi, Sürü Davranışı Teorisi ve Yatırımcı Duyarlılı̆̆ı Teorisi geliştirilmiştir (Kahneman ve Tversky, 1979).

Geleneksel finans teorisi yatırımcıların finansal kararlar alırken rasyonel davranış sergiledikleri ve beklenen fayda üzerinde odaklandığı varsayımı üzerine dayanmaktadır. Beklenen Fayda Teorisi belirsizlik altında karar vermede rasyonel seçimler için ve ekonomik davranışları açıklamada faydalı bir model olmuştur. Bu teori piyasalarda yer alan tüm bilgilerin fiyatlara yansıdığı, piyasaların etkin olduğu ve yatırımcıların bilgiye ulaşabilme hususunda eşit olduğunu ifade etmektedir.

1738 yılında Daniel Bernoulli tarafından temelleri atılan beklenen fayda teorisi, ardından John von Neumann ve Oskar Morgenstern tarafindan 1944 yilında "Theory of Games and Economic Behaviour” adlı çalışmada hayat bulmuştur (Mongin, 1997).

Beklenen fayda teorisinde; piyasanın etkin olduğu, yani piyasada oluşan fiyatların tüm bilgileri yansıttığı ve tüm yatırımcıların bu bilgileri eşit şekilde edinebilecek durumda oldukları belirtilmektedir (Fama, 1965).

Modern finans yaklaşımının aksine geleneksel finans, portföy oluşumlarında menkul kıymetlerin tercihinin fayda maksimizasyonuna dayandığ 1 esasına dayanmaktadır. Geleneksel portföy minumum risk maksimum fayda sağlayabilmek için portföyde yapılacak menkul kıymetlerin çeşitlendimesi ile sağlanacağı yaklaşımında ele alınmaktadır.

Geleneksel portföye karşı geliştirilen Modern Portföy Teorisi’nin ilkelerinin temelleri 1952 y1lında Harry Markowitz'in ünlü "Portfolio Selection" makalesi ile atılmıştır (Chhabra, Spring 2005). Bu makale ile bir portföyün beklenen getirisi ve riskinin nasıl ölçüleceğine dair 
yeni bir yaklaşım geliştirmiştir (Training, 2006). Bu teorinin temeli, belirli bir getiri seviyesinde riskin minimizasyonu veya belirli bir risk seviyesinde getirinin maksimizasyonunu amaçlamaktadır. Bu yeni portföy kuramı böylece, yatırımcının beklenen faydasının maksimize edilmesini sağlamaktadır (Pete ve Kasten, 2005).

Markowitz, belirli varsayımlar altında bir portföyün beklenen getirilerinin varyansının o portföyün riskini ölçmede kullanılabilecek iyi bir ölçü olabileceğini düşünmüş ve bir portföy varyansının ölçülmesi için gerekli formülü ortaya koymuştur. Söz konusu formül portföy riskinin nasıl düşürüleceğini açıklamakla kalmayıp, aynı zamanda etkin bir çeşitlemenin nasıl olması gerektiğini de ortaya koymaktadır (Konuralp, 2001).

Çeşitlendirme, getirileri birbirleri ile aynı zamanda, aynı yöne doğru değişiklik göstermeyen finansal varlıkların bir araya getirilmesi olarak tanımlanabilmektedir (Peterson, 1994). Geleneksel portföy kuramında, portföy ne kadar çok hisse senedine ve sektörlere dağıtılırsa çeşitlendirmenin o kadar başarılı olacağı ve riskin düşeceği kabul edilmekteydi. İlk defa Markowitz çeşitlendirmenin hisse senetlerinin getirileri arasındaki ilişkiye yani korelasyona dayanması gerektiğini ve belli bir hisse senedi adedinden sonra portföye dahil edilen hisse senetlerinin, portföy riskinin düşürülmesinde faydası olmayacağı görüşünü ortaya atmıştır (Konuralp, 2001: 250). Portföy, elde bulunan tüm varlıkları kapsamakta ve birden fazla yatırımı içermesi gerekmektedir.

\section{SÜRÜ DAVRANIŞI}

Sürü davranışı davranış biliminde çeşitli şartlar ve kurallar ile dayatılmış birtakım inançların, bir topluluk ya da grup tarafından yayılması şeklinde adlandırılabilmektedir. Bir başka ifadeyle sürü davranışı bir grup içerisindeki bireyler arasındaki düşünce ve davranış birliği olarak tanımlanmaktadır (Kameda vd., 2014). Sürü davranışı, bireyin başlangıçtaki değerlendirmesine karşı işlem yaptığında ve önceki işlemlerindeki trendi izlediğinde ortaya çıkan bir olaydır (Avery ve Zemsky, 1998). Finansal piyasalar aşırı değerlenmeyi ve beraberindeki çöküş ya da yükselişi genel itibariyle sürü davranışı (Bandwagon ya da herd behaviour) ile açıklanmaktadır (Ede, 2007). İnsanlar yatırım kararları alırken genellikle tercihlerini maksimum getiriyi sağlayacak şekilde şekillendirmek, portföylerini çeşitlendirmek ve riskten kaçınmak şeklinde ortaya koymaya çalışmaktadırlar. Ancak yapılan bilişsel hata ya da hatalardan dolayı yatırımcılar istediklerini uygulayamamaktadırlar. Özellikle BIST hisse senedi piyasaları üzerinde yapılan çalışmalarda borsada işlem yapan yatırımcıların ellerinde kazanç sağlayan hisse senedini olması gerekenden daha öncesinde ellerinden çıkardıkları, 
zararda oldukları hisse senetlerini ise olması gerekenden daha fazla ellerinde tuttukları gözlemlenmiştir. Bu durum sürü davranışından kaynaklanmakta olup, bu psikolojik durumda yatırımcılar karşılaştıkları durumlar karşısında olması gerekenden az ya da daha fazla reaksiyon göstererek hisse senetleri arasında duygusal bağ geliştirmektedirler. Bu noktada yatırımcılar sadece düşünceleri ile uyum gösteren bilgileri baz alarak, diğer bilgileri göz ardı ederek kendi düşünce ve sezgilerine göre hareket etmeyi tercih etmektedirler (Altunöz ve Altunöz, 2018).

Yatırımcıların aldıkları kararlar üzerinde etkili olan Sürü davranışının nedenleri aşağıda yer almaktadır (Doğukanlı ve Ergün, 2011: 228).

- Yatırımcının kendisinin sanki finansal varlığın fiyatını etkiyen farklı verilere sahip olmadığı şeklinde düşünüp diğer yatırımcıların bu bilgilere sahip olacağına inanması,

- Portföy yöneticilerinin performanslarının pazar getiri ortalaması ile karşılaştırılarak değerlendirip karar vermeleri

- Sürü davranışı, kişiler arasındaki korelasyonlu davranış modelleri oldukları için yatırımcıların diğerler yatırımcıların kararlarına uyma konusunda içsel tercihlerinin olması

Rasyonel karar üzerine kurulu Davranışsal finans literatüründe sürü davranışı yatırımcıların aynı durum karşısında aynı kararları vermeleri (spurious herding) ve farklı karar verme şansları varken diğerlerinin kararlarını takip etmeyi seçmeleri (intentional herding) olarak iki farklı açıdan ele almaktadır.

Faizlerin yükselmesi karşısında hisse senetlerin tüm yatırımcılara daha az cazip gelmesi yatırımcıların aynı durum karşısında aynı kararları vermelerine örnek olarak gösterilebilmektedir (Bikhchandani \& Sharma, 2001). Yatırımcıların bilinçli bir şekilde diğer yatırımcıların hareketlerini takip etmeleri ve aynı şekilde davranmaları ise bilinçli sürü davranışına örnek olarak gösterilebilmektedir. Burada dikkat edilmesi gereken nokta yatırımcıların bilinçli olarak hareket etmeleri sonuçlarının rasyonel olacağı anlamına gelmemektedir. Bu noktadan hareketle bilinçli olarak gerçekleşen sürü davranışı irrasyonel ve rasyonel iki farklı şekilde ele alınmaktadır (Chang vd., 2000).

\section{LITERATÜR}

Wang ve Canela (2006) gelişmekte olan piyasalar ve gelişmiş piyasalar üzerinde yaptıkları çalışmada sürü davranışı analizi beta sürü analizini kullanmışlardır. Çalışma 


\section{Kuzu, S. \& Çelik, İ. E.}

sonucunda gelişmekte olan piyasalarda sürü davranışının daha yüksek olduğunu tespit etmişlerdir.

Gavrilidis vd. (2007) 2000-2007 yılları arasında Arjantin krizinde MERVAL endeksi üzerinde yaptıkları çalışmada sürü davranışı analizi için beta sürü analizini kullanmışlardır. Çalışma sonucunda çalışmada kriz sırasında ve sonrasında sürü davranışına rastlamamışlardır.

Economou vd. (2011), sürü davranışını tespit etmek için 1998- 2008 yılları arasında Yunanistan, İtalya, Portekiz ve İspanya sermaye piyasalarında günlük verilerin alındığı Chang vd.'nin (2000) modeli yöntemi kullanmışlardır. Çalışma sonucunda edilirken İspanya'da sürü davranışına rastlanılınmazken, İtalya ve Yunanistan piyasalarında sürü davranışı tespit edilmiştir. Bunun yanında çalışmada aşırı yükselme dönemlerinde İtalya ve Yunanistan piyasalarında sürü davranışının arttığı tespit edilmiştir. Bunun yanında Portekiz'de sadece aşırı düşme dönemlerinde sürü davranışı olduğu gözlemlenmiştir.

Doğukanlı ve Ergün (2011) ise 2000-2010 yılları arasında alarak yaptıkları sürü davranışı analizini CSSS ve CSAD modellerini kullanarak, borsada sürü davranışını ele almışlardır. Çalışma sonucunda sürü davranışına ilişkin bulguya rastlamamışlardır.

Yao vd. (2013) çalışmalarında günlük ve haftalık verilerle Çin Sermaye Piyasasında Chang vd.'nin (2000) geliştirdikleri sürü davranışının varlığını tespit etmeye çalışmışlardır. Çalışma sonucunda yatırımcıların Çin Sermaye Piyasasında sürü davranışına rastlamışlardır. Bunun yanında Yatırımcıların yalnızca Çin Sermaye Piyasasında yer alan Shanghai-B ve Shenzhen-B pay piyasalarında sürü davranışı gösterdiklerini görülmüştür.

Mobarek vd. (2014), 2001-2012 tarihleri arasında Avrupa'da yer alan çeşitli borsa endeksileri üzerinde yaptıkları çalışmada Christie ve Huang (1995) ile Chang vd. (2000) yöntemleri kullanılarak sürü davranışı araştırılmıştır. Çalışma sonucunda krizler ve asimetrik piyasa koşullarında önemli miktarda sürü davranışı tespit edilmiştir.

Özsu (2015), 1998-2014 yılları arasında BIST endeksinden günlük ve gün içi pay senedi getirisinin ele alındığı çalışmada Christie ve Huang (1995) ve Chang vd. (2000) tarafından geliştirilen pay senedi getirilerinin yatay kesit değişkenliğine dayalı yöntemi kullanarak sürü davranışının yer alıp almadığg incelenmeye çalışılmıştır. Çalışma sonucunda BIST'de yükselen piyasalarda sürü davranışı gözlemlenirken, günlük ve gün içi verileri için yükselen ve alçalan piyasalarda sürü davranışına rastlanmamıştır. 
Doğukanlı ve Ergün (2015) 2000-2011 yılları arasında sektörel borsa verileri ele alarak yaptıkları çalışmada Hwang ve Salmon modelini kullanarak, borsada sürü davranışını ele almışlardır. Yapılan çalışma sonucunda Borsa' da dönemsel olarak sürü davranışı bulgularına rastlandiğı gözlemlenmiştir.

Akçaalan (2017), 1991-2016 dönemleri arasında sürü davranışlarını BIST hisse senedi piyasasını azalan ve yükselen piyasalar şeklinde ayırarak günlük veriler ile test etmeye çalışmıştır. Çalışmada istatistiki olarak getirilerin yatay kesit dağılımı analizi, kantil regresyon analizi ve durum-uzay modeli olmak üzere üç model kullanmıştır. Çalışma sonucunda, yatırımcıların piyasasında ve ayrıca yükselen ve alçalan piyasa koşullarında sürü davranışı gösterdikleri gözlemlemiştir. Bunun yanında Sürü davranışının asimetrisi test edildiğinde, yatırımcıların yükselen ve alçalan piyasalardaki iyi ve kötü ekonomik haberlere benzer şekilde tepki verdikleri sonucuna ulaşmıştır.

\section{VERİ VE METODOLOJİ}

\subsection{Veri}

Bu çalışmada 2000-2020/6 dönemleri boyunca BIST 100 de yer alan hisse senetlerinin günlük hisse senedi kapanış fiyatı, işlem hacmi verileri kullanılmıştır. Çalışmaya ilişsin veriler Finnet ve Bloomberg veri tabanından sağlanmıştır. Bunun yanında piyasa getirisinin hesaplanmasında BIST 100 endeksinin kapanış değerleri kullanılmıştır. Hisse senetlerinin günlük logaritmik getirileri kullanılarak sürü davranışının sergilenip sergilenmediği ortaya koyulmaya çalışılmıştır.

\subsection{Metodoloji}

Piyasadaki sürü davranışının varlığını tespit etmek için geliştirilen temel modellerden ikisi Christie ve Huang (1995) ile Chang vd.'nin (2000) sermaye piyasalarında sürü davranışını ölçmeye yönelik modelleridir (Christie ve Huang, 1995).

Piyasadaki sürü davranışının varlığını tespit etmeye yönelik modellerden ilki Christie ve Huang (1995) sürü davranışını ortaya koyabilmek için yatay-kesit standart sapma (YKSS) ölçüsünü kullanmıştır. Bu modelin temel beklentisi piyasada yatırımcıların varlık fiyatlarına ilişkin öngörülerini gizlemeleri ve bunu piyasada beklenen davranış ile dayandırmaları durumunda bireysel getiri ile piyasa getirisi arasında farklılık olmayacağı, bunun sonucunda beklenen yatay-kesit standart sapma ölçüsünden daha küçük sapmaların olabileceği temeline 
dayanmaktadır. Buna karşılık rasyonel varlık fiyatlama modelinde piyasa getirisinde yaşanan büyük değişimin varlık fiyatlarının getirilerin yayılım değerlerini etkilemesine neden olacaktır.

Christie ve Huang (1995) sürü davranışının ilgili varlığa yönelik düşük yatay-kesit standart sapma ölçüsünde ipucu verebileceği ancak bunun tam anlamıyla doğru sonucu veremeyeceğini ifade etmiştir. Bu modelde özellikle baskı altındaki finansal piyasalarda sürü davranışının tespit edilebilmesi için gün ya da hafta gibi zaman sürelerini açıklayan kukla değişkenli doğrusal regresyon denkleminden yararlanılması gerektiği ifade edilmektedir.

Piyasadaki sürü davranışının varlığını tespit etmeye yönelik modellerden bir diğeri ise Chang vd. (2000) tarafından ortaya konmuştur. Bu modelde toplam piyasa getiri yayılımı ve varlık getiri yayılımı arasındaki ilişki doğrusal olmayan regresyon denklemi kullanarak tespit edilmeye çalışılmaktadır. Bu modeli diğer modellerden farklı kılan özelliği ise doğrusal olmayan regresyon denklemi yanında yayılım ölçüsünü de modele dahil etmesidir. Chang vd. (2000), yatay-kesit standart sapma ölçüsü yerine yatay-kesit mutlak sapma ölçüsü kullanılması gerektiğini ifade etmiştir (Chang vd., 2000).

Chang vd. (2000), piyasa getirisi ile getiri yayılımı arasında ilişkinin ancak rasyonel varlık fiyatlama modellerinin kullanımıyla doğrusal bir şekilde ortaya koyulabileceği ifade edilmiştir. Buna karşılık modelde yatırımcıların kendi sezilerini baskılamaları durumunda ve piyasa davranışı çerçevesinde hareket etmeleri durumunda piyasa getirisi ile getiri yayılımı arasında ilişkinin uzun olmayacağını düşünmektedirler.

$\mathrm{Bu}$ yönteme göre öncelikle endeks ve pay senedi getirileri sonrasında aşağıdaki formülden yararlanarak hisse senetlerinin aylık yatay kesit mutlak sapmaları (Cross Sectional Absolute Deviation) hesaplanmaktadir.

$$
Y K M S_{t}=\frac{\sum_{i=1}^{N}\left|R_{i, t}-R_{m, t}\right|}{N}
$$

Yatay kesit mutlak sapmaları değerlerinin hesaplanması 1 nolu formülde verilmiştir.

$R_{i, t}=i$.hisse senedinin $t$ anındaki getirisini,

$\mathrm{R}_{\mathrm{m}, \mathrm{t}}=\mathrm{t}$ anmda piyasa getirisini igöstermektedir

$\mathrm{N}$ : hisse senedi sayıs1.

Endeks ve hisse senetlerinde sürü davranışının varlığını tespit etmek Christie ve Huang (1995) ve Chang vd. (2000) modellerinden faydalanılmıştır. Dağılımların hesaplanması için 
günlük ve gün içi kapanış fiyatları, günlük ve gün içi logaritmik getirilere çevrilmiştir. Her bir hisse senedinin $t$ anındaki getirileri hesaplamak için aşağıdaki formül kullanılmıştır.

$$
R_{i, t}=\operatorname{In} \frac{\left(P_{i, t}\right)}{\left(P_{i, t}-1\right)}
$$

Yatay kesit mutlak sapmaları, hisse senetlerinin dağılımını ölçmek için hisse senedi getirileri kullanılarak aşağıdaki formülle hesaplanmaktadır.

$$
\sqrt{Y K M S_{t}=\frac{\sum_{i=1}^{N}\left|R_{i, t}-R_{m, t}{ }^{2}\right|}{N-1}}
$$

Christie ve Huang (1995) ve Chang vd. (2000) modelleri için gerekli olan getiri yayılımı ölçüleri sırasıyla 1 ve 3 nolu formülden faydalanılarak hesaplanmaktadır. İlgili modellerde sürü davranışını tespit etmeye yönelik formüller 4 ve 5 denklemlerden izlenebilmektedir. Günlük ya da haftalık ekstrem getirilerin oluştuğu aşağı ve yukarı piyasa hareket günlerini incelemek için, iki kukla değişken kullanılmış olup, ilişki aşağıdaki regresyon denkleminde gösterilmiştir.

$$
Y K M S_{t}=\alpha+\beta^{L} \gamma_{t}^{L}+\beta^{U} \gamma_{t}^{U}+\varepsilon_{t}
$$

$\gamma_{t}^{L}$ t gününde BIST 100 endeks getirisinin düşük olduğu durumlarda, getiri dağılımının\% 1 ve \% 5 uç değerleri aralığında 1 değeri ya da aksi durumda sıfır değerini almaktadır. $\gamma_{t}^{U}$, t gününde BIST 100 endeks getirisini yüksek olduğu durumlarda, getiri dağılımının \% 1 ve\% 5 uç değerleri aralığında 1 değeri ya da aksi durumda sıfır değerini almaktadır. Ekstrem getirilerin olduğu zaman aralığı örneklemin \%1, \%5 veya \%10’u şeklinde belirlenebilmektedir.

Burada negatif ve istatistiksel olarak anlamlı olan $\beta^{L}$ ve $\beta^{U}$ katsayıları hisse senedi getirileri ile BIST 100 endeks getirisi arasındaki küçük dağılımların göstergeleridir. $\mathrm{Bu}$ durumda hisse senedi getirileri ile piyasa getirileri arasında benzer ilişkinin olduğu ve böylelikle BIST 100 endeksinde ekstrem getirilerin yaşandığı piyasa günlerinde sürü davranışının olabileceği sonucuna ulaşılmaktadır. Bunun yanında günlük ya da haftalık ekstremlerin yaşandığı piyasalarda sürü olmasa bile bu katsayıların düşük olması, hisse senedi getirilerinin, BIST 100 endeks getirisine göre daha az saptığı ve bunun sonucunda yatırımcıların sürü davranışı eğiliminde olduğunu ifade etmektedir.

Chang vd. (2000), yatırımcıların kendi sezilerini baskılamaları durumunda ve piyasa davranışı çerçevesinde hareket etmeleri durumunda piyasa getirisi ile getiri yayılımı arasında 
ilişkinin uzun olmayacağını aşağıdaki formülle test etmişlerdir. Aşağıdaki formül kullanılarak sürü davranışının varlığını araştırmak için ikinci dereceden bir denklem kullanılmıştır.

$$
Y K M S_{t}=\propto+\gamma_{1}\left|R_{m, t}\right|+\gamma_{2}\left|R_{m, t}^{2}\right|+\varepsilon_{t}
$$

5 nolu denklemde $\left|R_{m_{\imath} t}\right|$ benchmark portföyün ortalama getirisinin mutlak değerini, $\left|R_{m_{l} t}^{2}\right|$ ise karesini ifade etmektedir. $R_{m_{\imath} t}, \mathrm{t}$ anında ortalama piyasa getirisidir. Burada beklenti, sürü davranışı varsa getiri yayılımlarının piyasa getirisindeki bir artış ile birlikte düşmesi ya da piyasa getirisindeki düşüş ile birlikte yükselmesi yönündedir. Negatif ve istatistiksel olarak anlamlı $\gamma_{2}$ katsayısı doğrusal olmadığı ve bu durumda sürü davranışıyla varlığı ile sonuçlanacağını ortaya koymaktadır. Pozitif ve istatistiksel olarak anlamlı $\gamma_{2}$ katsayısı doğrusal olduğu ve bu durumda yatırımcıların yatırım işlemlerinde kendi görüşleri doğrultusunda karar aldıklarını göstermektedir. Böylelikle BIST 100 endeksi getirisi ile hisse senedi dağılımı arasında doğrusal bir ilişki yoksa sürü davranışı varlığının olduğu sonucuna varılabilir. Burada $\gamma_{1}$ katsayısı pozitif ve anlamlı olması durumunda $\left|R_{m, t}\right|$ ve $Y K M S_{t}$ arasında pozitif yönde ve istatistiki olarak anlamlı bir ilişkinin olması beklenmektedir.

\section{BULGULAR}

Tablo 1'de günlük piyasa getirilerinin $R_{m_{\Perp}, t}$ ve YKSS ilgili döneme ait istatistiki sonuçlar Tablo 1'de yer almaktadır.

Tablo 1. YKSS ve piyasanın uç değerleri arasındaki istatistiki sonuçlar

\begin{tabular}{|c|c|c|c|c|}
\hline $\begin{array}{l}Y K M S_{t}=\alpha+\beta^{L} \gamma_{t}^{L} \\
+\beta^{U} \gamma_{t}^{U}+\varepsilon_{t}\end{array}$ & $\mathbf{\% 1}$ & t-değeri & $\mathbf{\% 5}$ & $\begin{array}{c}\mathbf{t}- \\
\text { değeri }\end{array}$ \\
\hline$\propto$ & 10.4265 & 15.4265 & 9.6041 & 14.4685 \\
\hline$\beta^{L}$ & 0.3852 & 7.4571 & 0.3745 & 6.4157 \\
\hline$\beta^{U}$ & 9.4112 & 7.1591 & 5.6285 & 5.4252 \\
\hline Düzeltilmiş $R^{2}$ & 0.4356 & & 0.3214 & \\
\hline F-İstatistik & 58.5687 & & 72.6573 & \\
\hline
\end{tabular}

Tablo 1'de yer alan regresyon denklemi Piyasa getiri dağılımının alt ve uç değerlerin \% 1 ve $\% 5$ aralığında ekstrem hareketlerin yaşandığı piyasa hareketlerinin olduğu günleri tahmin edebilmek için kullanılmıştır. Tablo 1'de yer alan bilgilere göre $\beta^{L}$ katsayılarının varlık fiyatlama teorisi ile istatistiki olarak pozitif ve anlamlı değildir. Bir başka ifadeyle $\beta^{L}$ katsayılarının istatistiki olarak anlamlı çıkmadıklarından dolayı piyasanın alt ve uç değerlerin 
\% 1 ve \% 5 aralığında olmasının yatay kesit standart sapma üzerinde etkili olmadığı ifade edilebilmektedir. Bunun yanında piyasanın $\% 5$ uç değerler aldı̆̆ı durumlarda ise $\beta^{U}$ katsayılarının ise istatistiki olarak anlamlı olmasına karşın, pozitif katsayılar olmalarından dolayı süre davranışının sürü davranışının Türk hisse senedi piyasasında ele alınan dönemlerde geçerli olmadığını ortaya koymaktadır. Genel olarak ortaya çıkan durumda piyasalarda yaşanacak ekstrem durumlarının yatay kesit standart sapmayı azaltacağı hipotezi doğrulanamamakta ve kullanılan veri setinde ortaya koyulan yöntem ile sürü davranışına rastlanılmadı̆̆ı sonucuna ulaşılmıştır.

Tablo 2. İstatistiki özet bilgiler

\begin{tabular}{|l|l|l|l|l|l|l|l|l|}
\hline & Ort. & Med. & Max. & Min. & St.Sap & $\begin{array}{l}\text { Skewness } \\
\text { (Çarpılık) }\end{array}$ & $\begin{array}{l}\text { Kurtosis } \\
\text { (Basıkl1k) }\end{array}$ & $\begin{array}{l}\text { JB (Jarque- } \\
\text { Bera) }\end{array}$ \\
\hline$R_{m, t}$ & 0.0002 & 0.0001 & 0.1567 & -0.1045 & 0.0145 & -0.4576 & 6.4568 & $2241.13^{*}$ \\
\hline YKMS & 0.0243 & 0.0076 & 0.0945 & 0.0000 & 0.0045 & 1.8765 & 11.4762 & $14657.82^{*}$ \\
\hline
\end{tabular}

Tablo 2'de yer alan istatistiki sonuçları göre piyasa getirisi \%0.02 olduğu durumda, maksimum getisinin \%15.67, minumum getiri -\%10.45 değerlerini aldığı görülmüştür. Bunun yanında çalışmada yatırımcıların referans aldıkları ve gösterge niteli taşıyan BIST 100 endeksinin standart sapmasının \%1.45 olarak gerçekleşmiş olması, ilgili dönemlerde piyasada dalgalanmaların yüksek olduğunu ifade etmektedir. Bunun yanında Jarque-Bera test istatistiği serinin normal dağılım gösterip göstermediğini ölçmek için kullanılmaktadır. Jarque ve Bera testi bir Lagranj çarpanı prensipine dayanan bir test tipindendir. Test istatistiği örneklem basıklık ve çarpıklık ölçülerinin dönüşümlerinden elde edilmiştir. Sıfır hipotezi daha ayrıntılı olarak bir bileşik hipotezdir: beklenen çarpıklığın 0 değerde ve beklenen basıklık fazlalığının 3 değerde olacağı sıfır hipotezdir; çünkü bir normal dağılım için bu değerler gereklidir. Piyasa getirilerin ve YKSS değerlerinin normal dağılıma sahip olacağını iddia eden Jarque ve Bera test istatistiği $H_{o}$ hipotezi \%1 anlamlılık seviyesinde reddedilmiştir. Bu sonuca göre Piyasa getirileri ve YKSS değerlerinin normal dağılım göstermediği sonucuna ulaşılmaktadır.

\section{SONUÇ}

Geneksel yaklaşımda, finans literatüründe verimli piyasa hipotezi yaygın olarak kabul görmektedir. Bu hipotez yatırımcıların rasyonel davrandıklarını ve anormal getiri elde etmenin zor olduğunu varsayımı üzerine kurulmuştur. 
Bu çalışmada Borsa İstanbul'da günlük ve gün içi hisse senedi getirileri kullanılarak sürü davranışının olup olmadığı test edilmiştir. Çalışmada 2000-2020/6 dönemleri ile Borsa Istanbul'da işlem gören hisse senetleri ve piyasa göstergesi olarak BIST 100 endeksi kullanılmıştır. Sürü davranışı Christie ve Huang (1995) ve Chang vd. (2000) tarafından geliştirilen hisse senedi getirilerinin yatay kesit değişkenliğine dayalı yöntem kullanılarak analiz edilmiştir.

Borsa İstanbul'da yaşanan düşük volatilite hareketleri sürü davranışının altında yatan temel güdülerden biri olabilir. Özellikle Borsa İstanbul'da yatırımcıların piyasalarda ekstrem durumların olmadığı zamanlarda piyasa trendi çerçevesinde gözlem yaptıkları görülmektedir. Sürü davranışının temelinde yatan nokta yatırımcıların belirsiz ve değişken piyasa koşullarında diğer yatırımcıların kararlarına güvenmediği ve kendi inançlarına göre karar verdiğidir. Çalışmada kullanılan veri setinde ortaya koyulan yöntem ile sürü davranışına rastlanılmadığı sonucuna ulaşılmıştır. Bu durum diğer birçok çalışma ile paralellik göstermektedir. Özellikle piyasaların çok kırılgan olduğu ve volatilite hareketlerin sık yaşandığı dönemlerde yatırımcılarda korkunun yaygın olması ve bu korkunun daha fazla riske girilmemesi yönünde yarattığı his, ellerinde var olan yatırım araçlarını mümkün olduğunca ellerinden hızlı bir şekilde çıkarmaya neden olmaktadır.

\section{REFERENCES / KAYNAKLAR}

Akçaalan, E. (2017). Herd behavior in the Turkey stock market (Yüksek lisans tezi). İzmir Ekonomi Üniversitesi, İzmir.

Altunöz, U. \& Altunöz, H. (2018). Davranışsal ekonomi (nörofinans). Ankara: Seçkin Yayıncılık.

Avery, C. \& Zemsky, P. (1998). Multi- Dimensional uncertainty and herd behavior in financial markets. American Economic Review, 88(4), 724-748.

Bikhchandani, S. \& Sharma, S. (2001). Herd behavior in financial markets. IMF Staff Papers, 47(3), 279-310.

Chang, E., Chen, G. J. \& Khorana, A. (2000). Examination of herd behavior in equity markets: An international perspective. Journal of Banking Finance, 24(10), 1651-1679.

Chhabra, A. B. (2005). Beyond Markowitz: A comprehensive wealth allocation framework for individual investors. The Journal of Wealth Management, 7(4), 8-34.

Christie, W. \& Huang, R. (1995). Following the pied-piper: Do individual returns herd around the market? Financial Analyst Journal, 51(4), 31-37.

Doğukanlı, H. \& Ergün, B. (2011). İMKB'de sürü davranışı: Yatay kesit değişkenlik temelinde bir araştırma. Dokuz Eylül Üniversitesi Iş̧letme Fakültesi Dergisi, 12(2), 227-242. 
Economou, F., Kostakis, A., \& Philippas, N. (2011). Cross-country effects in herding behaviour: Evidence from four south European markets. Journal of International Financial Markets, Institutions and Money, 21(3), 443-460.

Ede, M. (2007). Davranışsal finans ve bireysel yatırımcı davranışları üzerine ampirik bir uygulama (Yayımlanmamış yüksek lisans tezi). Marmara Üniversitesi, İstanbul.

Fama, E. (1965). The behavior of stock market prices. Journal of Business, 38(1), 34-105.

Gavriilidis, K., Kallinterakis, B. \& Micciullo, P. (2007). The Argentine crisis: A case for herd behaviour? SSRN Electronic Journal.

Kahneman, D. \& Tversky, A. (1979). Prospect theory: An analysis of decision under risk. Econometrica, 47(2), 263-292.

Kameda, T., Inukai, K., Wisdom, O. \& Toyokawa, W. (2014). The concept of herd behaviour: Its psychological and neural underpinnings, Part II. In S. Grundmann, F. Möslein \& K. Riesenhuber (Ed.), Contract governance, Oxford: Oxford UniversityPress.

Konuralp, G. (2001). Sermaye piyasaları analizler, kuramlar ve portföy yönetimi. İstanbul: Alfa Basım Yayım Dağıtım Ltd. Şti.

Mobarek, A., Mollah, S. \& Keasey, K. (2014). A cross-country analysis of herd behavior in Europe. Journal of International Financial Markets, Institutions, and Money, 32, 107-127.

Mongin, P. (1997). Expected utility theory. Handbook of Economic Methodology, 342-350.

Özsu, H. H. (2015). Herd behavior on Borsa İstanbul (BISST): An empirical analysis (Doktora tezi). Dokuz Eylül Üniversitesi, İzmir.

Pete, S. \& Kasten, G. W. (2005). Post-modern portfolio theory. Journal of Financial Planning, 18(9), 74.

Peterson, P. P. (1994). Financial management and analysis. USA: McGraw-Hill, Inc.

Training. (2006). Modern portfolio theor. Bank Invesment Consultant.

Wang, D. \& Canela, M. (2008). Herd behavior towards the market index: Evidence from 21 Financial Markets. $(l$ Working Paper No. 776.). IESE Business School Working Pape.

Yao, J. M. \& He, W. P. (2013). Investor herding behaviour of Chinese stock market. International Review of Economics and Finance, 29, 12-29. 